\title{
economía y empresa a inicios de la república: los comerciantes extranjeros en arequipa (1821-1854)
} economy and enterprise at the beginning of
the republic: foreign merchants in arequipa (1821-1854)

\author{
Víctor Condori ${ }^{\star}$ \\ Universidad Católica San Pablo de Arequipa, Perú
}

\section{RESUMEN}

La prolongada guerra de Independencia en el Perú, favoreció la apertura del mercado nacional al comercio extranjero, posibilitando asimismo la llegada de numerosos hombres de negocios hacia la región de Arequipa, procedentes de distintos países de Europa como Inglaterra, Francia y Alemania. Tales empresarios, después de algunos años de residencia e inversiones en la ciudad, lograron tomar el control de las actividades de importación y exportación, desplazando definitivamente a los menos poderosos y poco influyentes comerciantes locales. En ese sentido, este trabajo de investigación busca conocerla complejidad de las actividades económicas desarrolladas por los principales comerciantes extranjeros asentados en la región de Arequipa durante la primera mitad del siglo XIX, así como su composición empresarial y participación en la economía regional, en una época marcada por la inestabilidad política y la angustia fiscal.

Palabras-clave: Arequipa. Independencia. Comercio. Importación. Exportación. Extranjeros. Europa.

\begin{abstract}
The prolonged war of Independence in Peru, favored the opening of the national market to foreign trade, also enabling the arrival of numerous businessmen to the Arequipa region, coming from different European countries such as England, France and Germany. Such entrepreneurs, after a few years of residence and investments in the city, managed to take control of import and export activities, definitely displacing the less powerful and few influential local merchants. In that sense, this research work seeks to know the complexity of the economic activities developed by the main foreign merchants settled in the Arequipa region during the first half of the 19th century, as well as their business composition and participation in the regional economy, in an era marked by political instability and fiscal anguish.
\end{abstract}

Keywords: Arequipa. Independence. Commerce. Import. Export. Foreign. Europe.

* Este trabajo forma parte de un proyecto sobre el comercio extranjero en la región de Arequipaentre1821 y 1850, el cual pudo realizarse gracias al Concurso de Proyectos de Investigación y Fondos Semilla 2018 de la Universidad Católica San Pablo de Arequipa.

Submissão: 15/09/2019; aprovação: 20/04/2020.

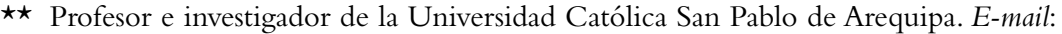
jvcondori@ucsp.edu.pe. ORCID: <https://orcid.org/0000-0002-8408-5114>. 
Que se vayan al diablo todos estos extranjeros que no acuden a un país nuevo sino para despojarlo y, después de burlarse de aquellos a quienes han arruinado, se retiran con su botín a las ciudades de Europa.

Flora Tristán, Peregrinaciones de una Paria (1838)

\section{La Intendencia de Arequipa}

Como consecuencia de las reformas administrativas diseñadas por los Borbones para sus dominios americanos, el año 1784 se introdujo en el Perú el sistema de Intendencias, por el cual todo el territorio del virreinato quedó dividido en siete circunscripciones, con sus respectivas autoridades político-militares, los Intendentes. Una de esas circunscripciones fue la Intendencia de Arequipa, ubicada en la parte meridional del virreinato, que se extendía desde el valle de Acarí hasta el desierto costero de Tarapacá, en el actual norte chileno; estuvo dividida en siete partidos o provincias, a saber Arequipa o Cercado, Camaná, Condesuyos, Caylloma, Moquegua, Arica y Tarapacá. Poseía la intendencia una extensa costa, de más de $1.000 \mathrm{~km}$ de longitud, muy apropiada para el comercio marítimo tanto legal como de contrabando, numerosas caletas y desembarcaderos, pero muy pocos puertos. Los centros urbanos más significativos, después de la capital fueron Camaná, Moquegua, Tacna y Arica, aunque con poblaciones inferiores a 7.000 habitantes (Wibel, 1975).

La capital de la Intendencia era la ciudad de Arequipa, "la muy noble y muy leal", "la fidelísima"; sede del gobierno político, administrativo y eclesiástico, la segunda ciudad más poblada del Perú después de Lima, con cerca de 37.000 habitantes (de ellas 22.000 personas vivían en el centro de la ciudad y un $71 \%$ registradas como españoles) $)^{1}$. Esta ciudad se ubica privilegiadamente en medio de un valle extremadamente fértil, a mitad de camino entre la costa y las tierras altas; entre Lima, Charcas y Chile, a una altitud de $2.320 \mathrm{msnm}$ y $100 \mathrm{~km}$ de distancia del Océano Pacífico.

En las últimas décadas de gobierno colonial, la economía arequipeña

1 La información sobre el censo realizado durante el gobierno del virrey Francisco Gil de Taboada y Lemos (1790-1796) la encontramos en Fisher (1981). 
fue orientándose en dirección a tres actividades fundamentales, a saber, la agricultura de exportación, el comercio de importaciones y en menor medida, la minería argentífera. La riqueza agrícola descansaba básicamente sobre el cultivo de la vid, insumo básico para la elaboración de los afamados vinos y aguardientes en los cercanos valles de Vítor, Majes y Moquegua, fuente principal de riqueza y prestigio de cientos de familias de la élite arequipeña; cuya producción se comercializaba casi de forma monopólica en numerosas ciudades y centros mineros del sur del Perú y la actual Bolivia, cuyos ingresos para la economía regional se estimaron en un millón y medio de pesos, muy por encima de la minería regional, que por esta misma época rendía cerca de 600.000 pesos anuales (Wibel, 1975). Asimismo, la segunda mitad del siglo XVIII fue testigo de una notable expansión del comercio de importaciones, de los llamados "Efectos de Castilla", gracias a diversos factores como, la política de liberación de puertos introducida por los Borbones en 1778 (que había incluido al puerto de Arica dentro de los 24 puertos liberados para el comercio directo con la península, junto al Callao) ${ }^{2}$; al establecimiento de una factoría de la mayor empresa de negocios de este siglo, la compañía general de los Cinco Gremios Mayores de Madrid ${ }^{3}$ y finalmente, a una importante migración de individuos de origen vasco, navarro y montañés hacia la región. Quienes proveídos de nuevas ideas en materia empresarial y sólidos vínculos comerciales en ciudades como Lima, Valparaíso, Buenos Aires y Cádiz lograron impulsar considerablemente dicha actividad. Estos "nuevos conquistadores españoles", entre los que se encontraban Juan de Goyeneche, Mateo Cossío, Antonio Alvisuri, Juan Fermín de Erreay y otros, lograron en poco tiempo posicionarse económica y políticamente, integrándose dentro de las familias tradicionales a través de ventajosos acuerdos matrimoniales y así consolidar una base económica y social suficientemente compacta, una verdadera comunidad de familias e intereses ${ }^{4}$.

2 La economía de la economía arequipeña a fines del periodo colonial se ha trabajado en Wibel (1975), Quiroz Paz-Soldán (1976), Brown (2008), Buller (2011) y Condori (2014).

3 Referente a las actividades de los Cinco Gremios en la ciudad de Arequipa, revisar Condori (2014).

4 Con relación a los migrantes peninsulares y sus negocios en Arequipa, es importante, Wibel (1975) y Brown (2008). 
A fines del periodo colonial y gracias a la confluencia de los factores arriba descritos, la Intendencia de Arequipa atravesó por un corto periodo de bienestar general como pocas regiones en el Perú. En 1808, su producción agrícola, minera y comercial alcanzó 2.154.000 pesos, la segunda en importancia después de Lima (2.190.349 pesos) y un ingreso per cápita de entre 16 y 24 pesos, muy por encima del promedio virreinal $(8 \text { pesos })^{5}$. Esta relativa bonanza expresada en un crecimiento de la viticultura, del comercio de importaciones y los ingresos aduaneros, se vio bruscamente interrumpida con el inicio de la guerra de Independencia y bien podría explicar aquella posición fidelista y conservadora tan particular de su élite, que la llevó a mantenerse cercana a los intereses del Reyhasta fines de 1824, cuando el último ejército realista de América del Sur fue completamente derrotado en los campos de Ayacucho ${ }^{6}$.

Con el establecimiento del sistema republicano a partir de 1825 , la Intendencia pasó a denominarse Departamento y el Intendente fue reemplazado por una nueva autoridad política y militar nombrada directamente por el gobierno central de Lima, el Prefecto. Sin embargo, aunque la nueva estructura político-administrativa regional continuó ocupando el viejo territorio colonial, conservando idéntico número de provincias y hasta sus denominaciones tradicionales, no pudo mantenerla notable prosperidad económica, ni su singular composición social. Ello se debió en primer lugar, a los efectos negativos ocasionados por la guerra de Independencia sobre actividades tan significativas como la agricultura, la minería y el arrieraje y en segundo, al ingreso progresivo de una pequeña pero cada vez más influyente población de origen europeo a la región.

\section{Los extranjeros en vísperas la Independencia}

La presencia de población extranjera en territorio hispanoamericano fue advertida desde el temprano siglo XVI. Según Peter Boyd-Bowman,

5 Estas cifras han sido tomadas de Anna (2003), Brown (2008) y Seminario (2016).

6 Los años decisivos de la independencia en Arequipa (1821-1824) y el comportamiento político de su élite son estudiados por Condori $(2009,2010)$. 
de los 45.374 individuos que migraron oficialmente hacia el Nuevo Mundo entre 1493-1579 cerca de 1293 (2.8\%) eran extranjeros; vale decir, portugueses, italianos, flamencos, franceses, griegos y alemanes (Body-Bowman, 1973). Quienes, portando algún permiso oficial o de manera encubierta, se incorporaron dentro de las distintas comunidades americanas como funcionarios, comerciantes, mineros, artesanos, soldados, clérigos o simplemente, aventureros. Un censo realizado en la capital del virreinato peruano a fines del siglo XVIII, indicaba que en Lima se hallaban residiendo 120 europeos de distintas procedencias, 53 italianos, 31 franceses, 21 portugueses, 6 irlandeses, 5 alemanes y solo 1 inglés (Bonfiglio, 2001).

Aunque en teoría, la legislación española era bastante prolija en cuanto a restricciones y controles con el fin de impedir toda forma de emigración extra peninsular hacia los dominios de ultramar, en la práctica la propia Corona, concedía determinados permisos de residencia a particulares con fines administrativos, educativos, religiosos, científicos y económicos, aunque siempre de forma limitada. Como ocurrió en 1788, cuando se autorizó el ingreso de 15 mineralogistas alemanes integrantes de la "Misión Nordenflicht" con el objetivo de reactivar y mejorar la producción argentífera del virreinato peruano (Fisher, 1977; Helmer, 1987). En ese sentido, no fue extraño encontrar en tierras americanas a individuos de otras naciones europeas, residiendo de forma provisional o permanente y a lo largo de los tres siglos de gobierno colonial. Sin embargo, se trataba de una población bastante reducida, por lo menos hasta fines del siglo XVIII. Para la segunda década del siglo siguiente, este número creció de manera considerable, tanto como su influencia en la economía y costumbres americanas, como consecuencia de las guerras de independencia en Hispanoamérica. En tales circunstancias, los puertos de uno y otro lado del continente abrieron sus puertas de manera definitiva para el ingreso de numerosos comerciantes y aventureros ingleses, franceses, alemanes y norteamericanos ${ }^{7}$.

La apertura comercial de las diferentes regiones del continente americano al capital extranjero no fue obra de agentes diplomáticos o re-

7 A fines del siglo XVIII, España abrió sus puertos coloniales a los llamados países neutrales y 1795 existía un tratado de Amistad, Límites y Navegación entre España y los Estados Unidos, ver Mazzeo (2000). 
presentantes oficiales de alguna monarquía europea, sino de audaces hombres de negocios, denominados por el profesor D.C.M. Platt "comerciantes aventureros", como los hermanos Parish Robertson y Hyslop (Platt, 1973). Quienes, en aquellos tempranos momentos, debieron marchar hombro a hombro con los ejércitos rebeldes, ligando su futuro al éxito de los movimientos independentistas y la protección de los jefes patriotas; por esa razón, los encontramos inicialmente operando en puertos y ciudades de la costa Atlántica y posteriormente en aguas del Pacífico. Primero en Brasil, Nueva Granada y Río de la Plata y luego de algunos años, en Chile y Perú ${ }^{8}$.

El establecimiento permanente de los comerciantes extranjeros en el Perú tuvo sus orígenes en un decreto promulgado por el virrey Joaquín de la Pezuela en 1820 que autorizaba el "comercio libre para los extranjeros" dentro del virreinato peruano (Villa Estévez, 2000). Curiosamente, cuando al año siguiente Lima cayó en poder de las fuerzas patriotas comandadas por el general San Martín, algunos de estos comerciantes se trasladaron más al sur, a la Intendencia de Arequipa ${ }^{9}$; que se convirtió por las circunstancias de la guerra en la única puerta de ingreso al último virreinato de América, con sede en el Cusco y que tenía bajo su control una parte del territorio peruano y toda la audiencia de Charcas, hoy Bolivia. En definitiva, durante los siguientes 4 años y hasta la culminación de la guerra de Independencia (1824), los comerciantes extranjeros se encontrarán divididos en dos comunidades, una establecida en la ciudad de Lima, controlada por los patriotas y la otra en Arequipa, bajo la autoridad de las fuerzas realistas.

Para ambos gobiernos la presencia de una pequeña comunidad de forasteros resultó indispensable y por ese motivo tolerada, no solo porque sus actividades mercantiles incrementaron los ingresos aduaneros (Paz-Soldán, 1975) o favorecieron el acceso a cualquier empréstito, sino también, por la posibilidad de conseguir su ministros y pertrechos mi-

8 Con respecto a las actividades de estos tempranos representantes del capital extranjero, básicamente inglés, en América Latina, Humphreys (1965), Donghi (1972) y Platt (1973).

9 Algunos comerciantes y firmas extranjeras en Lima durante esta época fueron,Alsop Wetmore y Compañía, Gibbs Crawley y Cía, Juan Moens, Juan Begg, Templeman Bergmam y Cía, Cochran, Robertson y Compañía, Huth Gruning y Compañía, entre otros. 
litares, indispensables para la culminación definitiva de la guerra (Miller, $1975)^{10}$. Esta penosa y generalizada situación fiscal, fue muy bien aprovechada por algunos de estos comerciantes a la hora de fijar los precios de sus mercancías, solicitar exoneraciones o privilegios aduaneros o incluso, cuando había que satisfacer la demanda de cualquiera de los dos ejércitos en pugna, patriotas o realistas, según se presenten las oportunidades en el mercado o convenga a sus intereses particulares. Frente a aquella volubilidad tan manifiesta exhibida portales personajes y hasta cierta desfachatez, un alto oficial del ejército patriota, el muy observador general inglés Guillermo Miller, manifestaba en sus memorias:

Como comerciantes, hicieron muy bien a la verdad en aprovecharse cuanto pudieron del ventajoso mercado que les ofrecían las circunstancias; pero pretender después que lo hicieron por su ardiente patriotismo sin miras de interés algunos, es cosa en que no puede convenirse. Es cierto que muchos desplegaron la liberalidad de sentimientos...Cuando estos por desgracia se ponían en contradicción, la pobre simpatía se iba frecuentemente de paseo y los realistas recibían el surtido de municiones de guerra y pertrechos que necesitaban, siempre que podían ofrecer precios ventajosos. (Miller, 1975, p. 179)

\section{Los comerciantes extranjeros en Arequipa}

Los primeros comerciantes de origen no peninsular arribaron a la región de Arequipa a comienzos de la década de 1820, antes de la liberación definitiva del Perú y continuaron llegando a lo largo de todo el siglo XIX, previa escala en algún país de América del Sur o directamente desde Gran Bretaña, Francia, Alemania, Países Bajos olos Estados Unidos (Witt, 1992). Aunque representaron un número significativo en las ciudades y puertos donde se establecieron, no se trató de un grupo

10 En noviembre de 1824, los comerciantes ingleses Luis Stevenson, Guillermo Turner y Santiago Ygualt, entregaron 1071 pesos en paños y caserillo, para "el vestuario del batallón de cazadores del rey”. Un mes después Ambrosio Ibáñez y Juan Moens, 12.364 pesos, "que importaron los efectos suministrados al batallón Real Felipe y a los escuadrones de cazadores, dragones y voluntarios de la costa para vestuario" (Archivo Regional de Arequipa (ARAR), Caja Nacional de Hacienda, Libro Mayor 1824, Hacienda Común. Data, fol. 114). 
homogéneo y mucho menos compacto e incluso, tratándose de los nativos de una misma nación ${ }^{11}$. En ese sentido, por la magnitud de sus negocios, el momento de su arribo y el tiempo de permanencia en la región, podemos clasificar los en tres grupos: los "comerciantes aventureros", los grandes mayoristas o almaceneros y los medianos comerciantes.

\subsection{Los comerciantes aventureros}

A diferencia de aquellos temerarios personajes mencionados por Platt y Humphreys, en sus estudios acerca del comercio británico, estos nuevos aventureros arribaron a las costas arequipeñas atraídos sobre todo por las condiciones favorables que presentaba el país gracias a la política "liberal" de los últimos virreyes, Joaquín de la Pezuela y José de la Serna. Aunque procedían de distintas naciones europeas, la gran mayoría eran británicos (ingleses, escoceses e irlandeses), formados empresarialmente en Londres o Liverpool, quienes llegaron progresivamente como sobrecargos en algunos de los numerosos barcos que hacían su escala en el puerto de Quilca o simplemente como representantes de sólidas casas comerciales ya establecidas en Lima o Valparaíso ${ }^{12}$. Dentro de este temprano grupo, encontramos a Tomás Crompton, Guillermo Hodgson, Roberto Page, Santiago Ygualt, Guillermo Turner, Federico Marriot, Juan Robinson, Luis Stevenson, Samuel Haigh, entre otros (Witt, 1992). De todos ellos, solo Tomás Crompton y Samuel Haigh, poseían una larga experiencia en territorio americano, habiendo residido durante muchos años en Buenos Aires yValparaíso, respectivamente ${ }^{13}$.

La aparición de estos comerciantes en un primer momento, no representó un cambio sustancial en la economía y sociedad regional, mucho menos, significó para ellos su consolidación económica o un

11 En 1833 la viajera Flora Tristán en relación a los franceses que encontró en Arequipa, decía: "Estos hombres se detestan, se destrozan a cual más. Durante los siete meses que pasé en Arequipa, he tenido tiempo de juzgar hasta dónde puede llegar el odio de los hombres cuando está excitado por la rivalidad y la envidia.” (Tristán, 1997, p. 242).

12 ARAR, Intendencia, Causas Administrativas 108. Caja Nacional de Hacienda. Libro Mayor de la Caja de Arequipa 20.

13 Samuel Haigh, comerciante y viajero inglés, visitó en 1817 el puerto de Valparaíso y posteriormente Buenos Aires antes de llegar a Arequipa. En 1831 escribió en Londres una relación de sus viajes. Sobre su estancia en el Perú (Haigh, 1967). 
rápido enriquecimiento, contrariamente, su crecimiento dentro de la ciudad estuvo claramente limitado, no solo por el avance de la guerra de independencia en sus últimos años ${ }^{14}$, sino también, por la presencia de grandes comerciantes importadores de origen peninsular como Lucas de la Cotera y Ambrosio Ibáñez, quienes gracias a sus estrechos vínculos políticos con las autoridades locales y virreinales, sus fuertes contribuciones y donativos al gobierno español y el abastecimiento permanente del ejército realista con tejidos y $\operatorname{armas}^{15}$, lograron monopolizar la casi totalidad de cargamentos extranjeros que llegaban a la región, provenientes de distintas partes de Europa.Y como Lucas de la Cotera, introducir cerca de 500.000 pesos en mercancías anualmente, para su distribución en el sur del Perú y Charcas ${ }^{16}$. En la práctica, había muy poco espacio para ser aprovechado por los recién llegados en ese momento. De otro lado, tal era el ascendiente y prestigio de Cotera dentro de la región que, muchos comerciantes extranjeros se vieron en la necesidad de utilizar sus influencias y garantías ante las autoridades españolas a fin de internar ciertas mercancías o salvaguardarlas de algún intento de confiscación ${ }^{17}$.

Las verdaderas oportunidades para aquellos tempranos comerciantes foráneos se presentaron a partir del año 1824; entre otras razones, debido, por un lado, a las mayores concesiones en materia de derechos de importación otorgadas por el gobierno virreinal del Cusco, cada vez

14 En setiembre de 1823, Arequipa fue invadida por tropas colombianas al mando del general Antonio José de Sucre y durante más de un mes, 3000 soldados ocuparon la ciudad, las actividades quedaron paralizadas, algunas propiedades fueron saqueadas y los vecinos más prominentes fueron obligados a pagar una fuerte contribución de guerra.Ver Condori (2009).

15 En noviembre de 1821, Lucas de la Cotera firmó un contrato con la Real Hacienda de Arequipa a fin de proveer al ejército virreinal con 6.000 fusiles, 20.000 uniformes, 4.000 sables de caballería, 6.000 pesos en medicina y hasta una imprenta; en un plazo no menor de cinco meses para las armas, ni mayor a once para lo restante(ARAR, Protocolos Notariales, Manuel Primo de Luque 717, fol. 630).

16 El español Lucas de la Cotera fue el más importante e influyente comerciante de Arequipa entre 1821-1824, sus buenas relaciones con las autoridades españolas, incluida su amistad con el propio virrey La Serna y sus enormes ingresos, lo llevaron a convertirse en el principal abastecedor y financista del gobierno virreinal en la agonía de su presencia en el Perú. Revisar Condori (2011).

17 ARAR, Protocolos Notariales, Manuel Primo de Luque 721, folios 709 y 764. Libro Mayor de la Real caja de Arequipa 20, Hacienda Común, fol. 29. 
más urgido de ingresos en la fase final de la guerra y por el otro, a la derrota definitiva de este gobierno, que provocó la salida precipitada de muchos empresarios peninsulares, entre ellos de Lucas de la Cotera. Según un informe del cónsul británico en el Perú, Thomas Rowcroft, a fines de ese año se encontraban instaladas en la ciudad 16 casas comerciales inglesas, cuyos intereses en créditos y propiedades alcanzaron cerca de tres millones de pesos (Humphreys, 1940). Pero, había que esperar mucho más. Entre 1825 y 1827, el departamento de Arequipa fue prácticamente inundado por una avalancha de mercancías europeas consignadas desde Londres, Liverpool, Baltimore, Burdeos y Valparaíso a nombre de sus representantes en la ciudad, en volúmenes que sobrepasaron largamente la propia capacidad de consumo de los mercados de la región, ocasionando en consecuencia, una brusca caída en los precios. Así lo denunció en 1826, el nuevo cónsul Charles M. Ricketts:

El espíritu de especulación, y las descripciones exageradas de la riqueza del Perú, condujeron a la consignación de muchos barcos con cargamentos que excedía largamente las necesidades del público y su capacidad de pago. La consecuencia es que las mercaderías británicas generalmente han visto reducir sus precios y muchas de ellas no devolverán ni su precio de costo. (Bonilla, 1975, p. 22)

De manera paralela, algunos de estos comerciantes aventureros como Tomás Crompton, Guillermo Hodgson, Samuel Haigh, Roberto Page y Santiago Ygualt, constituyeron importantes compañías mineras, a nombre propio o de inversionistas londinenses, a fin de reactivar y explotar algunos yacimientos de oro y plata paralizados y abandonados antes del inicio de la guerra; como por ejemplo, las legendarias minas de Huantajaya, ubicadas en el desierto de Tarapacá y propiedad de la familia de la Fuente y Loayza ${ }^{18}$.

Lamentablemente, en medio de esta vorágine de mercancías e inversiones especulativas que se observó en gran parte de América Latina, estalló la crisis financiera del mercado de Londres en diciembre de 1825, que trajo como consecuencia la suspensión de créditos de la banca londinense, la reducción de consignaciones mercantiles y el abandono

18 ARAR, Protocolos Notariales, Rafael Hurtado, legajo 675, folios 235 y 257-258. Manuel Primo de Luque, 722, fol. 587. 
de las prometedoras inversiones mineras ${ }^{19}$. Aunque los efectos de la crisis se observaron en la región un poco más tarde, ella se manifestó inevitablemente en, la paralización de varios proyectos mineros, la reducción de consignaciones y la desaparición progresiva de aquellos tempranos comerciantes comisionistas; bien sea porque regresaron decepcionados a Europa, cambiaron de actividad o se trasladaron a otras ciudades, en busca de nuevas y mejores oportunidades ${ }^{20}$. En consecuencia, para fines de la década de 1820 los arequipeños fueron testigos una vez más de la emergencia de grandes casas comerciales, como a fines del siglo XVIII; pero a diferencia de los primeros comerciantes aventureros, estos se encontraban más afianzados, tenían mayores conocimientos de la realidad económica, geográfica y cultural de la región y sobre todo, poseían sólidos vínculos mercantiles y representantes en ciudades como Lima, Valparaíso, Buenos Aires, Río de Janeiro, Baltimore, Liverpool, Londres, Burdeos, Hamburgo y Bremen.

\subsection{Los grandes almaceneros}

Un censo realizado en la provincia de Arequipa el año 1847, con el objeto de conocer la realidad ocupacional de su población, señaló que dentro de la ciudad 3445 personas ejercían alguna profesión u oficio remunerado y de ellos, cerca de554 (16\%) se dedicaban a actividades relacionadas con el comercio, bien sea como grandes importadores o almaceneros, medianos comerciantes o simplemente, tendederos ${ }^{21}$. Para una población urbana calculada en 15.175 habitantes, el número de personas dedicadas a este oficio resultó bastante elevado, prácticamente existía 1 comerciante por cada 30 habitantes. Pero, la realidad de aquel universo mercantil también decía que, solo cinco individuos estuvieron considerados dentro de la primera categoría, vale decir, como almaceneros y todos ellos eran europeos. Se trataba de las casas comerciales inglesas, Jack Hermanos, Guillermo Gibbs y Tomás Mac Laughlin; la francesa de Santiago Le Bris/Andrés Viollier y la alemana de Cristóbal

19 Con relación a la crisis del mercado londinense de 1825-1826, revisar Marichal (1992).

20 ARAR, Protocolos Notariales, Matías Morales 751, fol. 135; 753, fol. 71. Corte Superior, Causas Civiles 37, 7 mayo 1830.

21 El Republicano, Tomo 21, Número 36, 23 mayo 1847. 
Guillermo Schütte. Estas cinco firmas, durante aquellos años, llegaron a controlar más del $90 \%$ de las mercancías introducidas por el puerto de Islay ${ }^{22}$.Sin embargo, tal número no se mantuvo constante y al igual que su composición, fue variando a lo largo de los años. Como lo podemos observar en el siguiente cuadro.

\begin{tabular}{|c|c|c|c|}
\hline Cuadro $1-$ Grandes comerciantes o almaceneros de Arequipa & \\
\hline AÑo & Europeos & ArEQuipeños & Peninsulares \\
\hline 1827 & 7 & 2 & 1 \\
\hline 1830 & 8 & 2 & 1 \\
\hline 1833 & 7 & 1 & -- \\
\hline 1836 & 7 & 1 & 1 \\
\hline 1841 & 8 & 1 & -- \\
\hline 1847 & 5 & -- & 1 \\
\hline
\end{tabular}

Fuentes:Wibel, 1975, 478.El Republicano, Tomo 21, Número 36, 23 mayo 1847.

* Los grandes almaceneros no fueron clasificados de esta forma hasta 1833.

Con la excepción de Tomás Mac Laughlin, quien residió durante muchos años en la ciudad de Tacna, los cuatro restantes se establecieron en Arequipa antes de la caída del gobierno español, previa escala en Lima oValparaíso, donde con anterioridad habían constituido una dependencia comercial ${ }^{23}$, salvo el escocés Juan Jack, que llegó directamente desde el puerto de Liverpool. La primera casa extranjera en Arequipa apareció en octubre de 1821 y fue fundada por el comerciante francés Santiago Le Bris. Curiosamente, aunque las actividades de estas grandes firmas empezaron a registrarse a partir de 1824, ellas se mantuvieron dentro de un nivel de moderación y prudencia frente al desorden especulativo de los años posteriores a la Independencia y será recién a partir de 1828, con la desaparición de los comerciantes aventureros y el restablecimiento de las importaciones, pasada la crisis londinense, que tales actividades se

22 En 1849 la aduana principal de Islay recaudó 163.496 pesos por concepto de derechos de importación y exportación, de los cuales 158.422 pesos provenían de 5 almaceneros; el año 1852, recaudó 238.190 pesos, de ellos, 212.806 aportaron 6 almaceneros (ARAR, Tesorería de Arequipa, Libro Manual 1849 y Libro Mayor 1852).

23 En 1820 se constituyó la casa Le Bris-Bertehaume en Valparaíso; en 1822 la casa Gibbs, Crawley, Moens y Compañía en Lima y ese mismo año, la casa Schütte Post en Valparaíso. 
multiplicaron notablemente en volumen y frecuencia, desplazando con el tiempo a algunos comerciantes locales, sobrevivientes de épocas anteriores, como Ambrosio Ibáñez, Manuel Marcó del Pont y el más notable de todos, Juan Mariano de Goyeneche y Barreda ${ }^{24}$ (representante de la más acaudalada familia arequipeña, propietaria urbana, terrateniente y principal fuente de crédito local), hasta tomar el control definitivo de las actividades de importación y exportación una década más tarde. El siguiente cuadro elaborado en base a los derechos de importación y exportación pagados por los principales comerciantes establecidos en la ciudad de Arequipa corrobora dichas afirmaciones.

\begin{tabular}{|l|r|r|r|r|r|}
\hline Cuadro 2 - Derechos pagados en la aduana de Islay entre 1836-1840 (Pesos) \\
\hline Casa de Comercio & 1836 & 1837 & 1838 & 1839 & 1840 \\
\hline Jack, Hermanos y Compañía. & 12.257 & 33.607 & 34.467 & 27.227 & 53.244 \\
\hline Tayleur, Mac Laughlin y Compañía. & 6.836 & 18.203 & 17.060 & 9.444 & 26.938 \\
\hline Santiago Le Bris/Andres Viollier & 7.761 & 4.844 & 19.262 & 14.462 & 23.800 \\
\hline Gibbs, Crawley y Compañía & 5.970 & 7.943 & 11.716 & 10.929 & 18.704 \\
\hline Juan Moens y Compañía & 3.165 & 10.833 & 8.817 & 6.440 & 18.584 \\
\hline Cristóbal G. Schütte y Compañía & 1.000 & 6.599 & 11.268 & 3.179 & 150 \\
\hline José Marcó del Pont (argentino) & 2.503 & 2.968 & 6.959 & 2.843 & -- \\
\hline Dickson, Price y Compañía & 816 & 1.167 & 4.407 & 5.908 & -- \\
\hline
\end{tabular}

Fuente:ARAR. Libros de la Tesorería de Arequipa, 1836, 1837, 1838, 1839 y 1840.

Una particularidad de las mencionadas empresas, que bien puede explicar el éxito alcanzado -exceptuando la Casa Gibbs, manejada por administradores asalariados o socios menores - estuvo, en la conducción directa del negocio por los mismos propietarios; lo que permitió ahorrar varios miles de pesos correspondientes al salario de un administrador y de paso tener un control permanente y cercano del mismo, vale decir, de su personal dependiente, la cantidad y calidad de las mercancías, las ventas, los precios, la demanda, las quejas y hasta el cobro de deudas. Esta ventaja comparativa, posibilitó invertir rápidamente en algún negocio ocasional y lucrativo, como la adquisición de una vivienda, un terreno

24 ARAR, Protocolos Notariales, Nazario de Rivera 825, folios 61-62, 86, 112, 115 y 149. Libro Manual 23, fol. 90, 2 de junio de 1827. 
agrícola o alguna valiosa mercancía, a precios rebajados y en las cantidades que fuesen necesarias, sin la obligación de tener que esperar varios meses por la aprobación o rechazo de los socios principales en Lima, Valparaíso o Inglaterra ${ }^{25}$. Asimismo, la administración directa posibilitó a sus dueños alcanzar algunos compromisos formales con las autoridades de gobierno, locales y nacionales, a fin no solo de favorecerlas con diversos recursos materiales y pecuniarios ${ }^{26}$, sino también, poder conseguir de ellas jugosos contratos de construcción de necesarias obras públicas, como muelles, cañerías de agua o ferrocarriles, o mejor aún, la obtención de una envidiable consignación para la venta de guano hacia los ricos mercados de Europa y los Estados Unidos (Condori, 2016a).

Como puede imaginarse, tales condiciones permitieron a sus propietarios, además de colocar sus respectivas negociaciones en la cúspide del comercio regional, acumular en pocos años grandes fortunas personales. Una vez convertidos en hombres ricos, regresaron a Europa, donde sus fabulosas ganancias fueron invertidas en acciones de bancos, compañías navieras, ferrocarrileras y bienes raíces, retirándose progresivamente de la vida mercantil ${ }^{27}$. Antes de ello, dejaron la administración de sus firmas a algún pariente o empleado destacado, pero no completamente, porque continuaron gozando de alguna participación en ellas. Así se explica, por un lado, porqué dichas firmas continuaron expandiéndose a lo largo del siglo y por el otro, los cambios en la razón social

25 ARAR, Protocolos Notariales, Manuel Primo de Luque 725, fol.131. El Republicano, Tomo 25, Número 401, 14 junio 1851.

26 En setiembre de 1844 el gobierno del Directorio encabezado por el general Manuel Ignacio Vivanco reconoció diferentes créditos por valor de 67.096 pesos, obtenidos mediante anticipos de dinero a cuenta de derechos de importación y exportación adeudados en la Aduana de Islay, por parte de los siguientes comerciantes, Jack, Hermanos y Compañía por 24.081 pesos; Thomas Mac Laughlin y Compañía, 16.313; Gibbs, Crawley y Compañía, 14.643; Federico Marriot y Compañía, 5.158; Jerónimo Guillermo Harmsen y Compañía, 2.979; Andres Viollier y Compañía, 2.034; Guillermo Turner y Compañía, 643 y Santiago Romero por 311 pesos (El Republicano, Tomo 19, Número 11, 2 setiembre 1844).

Los casos más emblemáticos al respecto son la de los hermanos Juan y Santiago Jack. Juan, al regresar a Inglaterra en 1836 invirtió su fortuna en acciones de ferrocarril y en 1852 compró la mansión de Dale Park de Arundel en Sussex. Santiago por su parte, invirtió buena parte de su fortuna en bienes raíces y en 1865 adquirió la magnífica finca de Rosehaugh de 6.400 acres al oeste de Avoch, valorada en 145.000 libras esterlinas, revisar Mills (1997). 
de estas negociaciones. Por ejemplo, la casa fundada por Santiago Le Bris en 1821, se denominó a partir de 1838, Andrés Viollier y Compañía y desde 1850 en adelante, Luis Braillard y Hermanos, los dos últimos fueron empleados de la casa (Condori, 2013).

\subsection{Los medianos comerciantes}

Entre los residentes extranjeros en Arequipa dedicados a la actividad comercial, en la primera mitad del siglo XIX, el grupo más abultado lo conformaban aquellos que hemos denominado medianos comerciantes o simplemente tenderos, a decir de la documentación de la época; que hacía referencia a aquellos que no siendo almaceneros eran propietarios de una o más tiendas dentro de la ciudad. Acerca de su número, dependiendo de la situación política o económica que se vivía en ese momento, este llegó a fluctuar entre 15 y 25 individuos en promedio, frente a los casi 350 de sus homólogos locales; pero, hacia fines de la década de 1840 esta cantidad se redujo aún más, hasta apenas bordear la decena. Aunque seguían arribando extranjeros, ya no era el "giro comercial" su principal aspiración (Meneses, 2014). Una buena parte de ellos, llegaron por la época de la apertura del comercio colonial a todos los extranjeros, decretada por el virrey Joaquín de la Pezuela y continuarían haciéndolo en las décadas posteriores, pero en diferentes situaciones: como mercaderes independientes, socios menores, administradores o dependientes de alguna firma ya establecida en la ciudad. No obstante, encontrarse en este grupo individuos de distintas nacionalidades hubo un predominio notable de súbditos de la monarquía británica, por lo menos en esta primera mitad de siglo. Entre los más reconocidos de ellos tenemos a Samuel B. Mardon, Juan Moens, Federico Marriot, Guillermo Turner, Guillermo Mathews, Juan Federico Johnson, Juan Ward, Juan Robinson, Diego Gibson, Guillermo Spence, Juan Bautista Jacquet, Juan Bautista Poncignon, Jerónimo Guillermo Harmsen, José Marcó del Pont, entre otros (Witt, 1992).

Pese a su reducido número ( $5 \%$ del total de comerciantes), no se trató de un grupo homogéneo, compacto y mucho menos hermético, en la medida que su posición económica dentro de la región fue variando en distintas direcciones y a lo largo de los años; por ejemplo, algunos de ellos como los ingleses Samuel Mardon, Juan Moens y Federico 
Marriot, llegaron a estar ranqueados como almaceneros aunque por poco tiempo y otros, siendo solo empleados de alguna firma se independizaron y posteriormente abrieron sus negociaciones, llegando a convertirse en grandes mayoristas, como el nativo de Hamburgo Jerónimo Guillermo Harmsen, ya en la segunda mitad del siglo XIX ${ }^{28}$. Pero, también estuvieron aquellos que fracasaron completamente en los negocios y tuvieron que dedicarse a otras actividades como el inglés Juan Ward, agente marítimo en el puerto de Islay durante muchos años o peor aún, declararse en "quiebra legal" o "pobres de solemnidad", al no tener como hacer frente los procesos judiciales emprendidos en su contra por sus numerosos acreedores, como le ocurrió al francés Juan Bautista Jacquet ${ }^{29}$.

Los miembros de este grupo tan heterogéneo de medianos comerciantes, actuaban básicamente como intermediarios, apoderados o dependientes, tanto de los grandes almaceneros arequipeños como de reconocidas firmas extranjeras establecidas en Lima, Tacna o Valparaíso; pero a su vez, establecieron fructíferos vínculos crediticios con pequeños tendederos y mercachifles locales, comerciantes itinerantes o residentes en algunos pueblos y ciudades del interior. Asimismo, con el objetivo de mejorar su situación financiera, no en pocas ocasiones buscaron asociarse entre ellos y formar alguna que otra compañía comercial, así surgieron las sociedades denominadas Turner-Stevenson, Turner-Marriot, Ward-Johnson y Gibson-Power ${ }^{30}$. Lamentablemente, tuvieron corta duración y adversos resultados. Estos emprendimientos poco exitosos en materia comercial, no favorecieron la acumulación de grandes fortunas dentro de este sector y quizá ello explique su situación de medianía permanente y algunas peculiaridades a destacar. Por ejemplo, muchos de ellos terminaron estableciéndose dentro de la región, tomando en matrimonio a señoritas de la élite local, varias de ellas poseedoras de un rico patrimonio familiar y mejores relaciones sociales; así también, buscaron incursionar en otras actividades económicas tradicionales como la agricultura o la minería, asociados muchas veces con sus nuevos pa-

\footnotetext{
28 Archivo General de la Nación (AGN), Matrícula de Patentes 357, año 1847, fol. 15.

29 ARAR, Corte Superior de Justicia, Causas Civiles 139, 22 diciembre 1840. Asimismo, Causas Civiles 191, 5 mayo 1846.

30 ARAR, Protocolos Notariales, Manuel Primo de Luque 720, 20 noviembre 1823, fol. 1047; 725, 9 julio 1828, fol. 399 y Mariano Polar 793, 19 octubre 1831, fol. 352.
} 
rientes políticos. Esos fueron los casos de Samuel B. Mardon casado con María de la Candelaria García y Ureta, Juan Federico Johnson con Agustina Ureta, Juan Moens con Paula Prado Zavalaga, Federico Marriot con Bernardina Rivero y Besoaín, Juan Robinson con Rosalía Velarde y Diego Gibson con Juana Estremadoyro y Vásquez (Witt,1992).

\section{Actividades económicas}

Durante primera mitad del siglo XIX en materia económica, el Perú atravesó por una profunda crisis motivada entre otras razones por, la ruina de las principales actividades de raigambre colonial, la ausencia de créditos e inversiones extranjeras y la permanente angustia fiscal de los primeros gobiernos de turno. En ese contexto tan enrevesado, la economía regional será el escenario de la eclosión de numerosas compañías particulares y proyectos de desarrollo estatal ${ }^{31}$, cuyo éxito o fracaso dependerán indistintamente de la coyuntura económica internacional, la situación política imperante en la región, la capacidad de negociación de las empresas e incluso, algunas peculiaridades propias de la personalidad de los empresarios, vale decir, si eran moderadamente cautelosos o arriesgados hasta la temeridad.

En relación al comercio, además de las actividades inherentes a esta ocupación como la importación y distribución de efectos europeos y la exportación de materias primas y metales preciosos, los comerciantes extranjeros, se involucraron en numerosos quehaceres, algunos vinculados y otros completamente ajenos a su profesión, como la compra o arrendamiento de haciendas, para utilizarlas en la producción de cultivos industriales(algodón y vid) o de pan llevar (trigo y maíz); la compra y venta de propiedades urbanas y rurales; la obtención de pequeñas embarcaciones a fin de emplearlas en el transporte de mercancías o fertilizantes hacia los puertos y valles de la costa; la adquisición de escombros mineros para su exportación a Europa; la habilitación minera a empresarios del ramo con insumos o herramientas y además de todo lo mencionado, el expendio de pasajes marítimos, en representación de algunas

31 Sobre las empresas económicas en Arequipa durante estos años, revisar Condori (2014). 
embarcaciones surtas en el puerto de Islay (Condori, 2013;2016a). Por otra parte, trataron de evitar de cualquier forma el desvío de capitales propios hacia la explotación directa de algún yacimiento minero, de manera individual o colectiva; pero sobre todas las cosas, buscaron eludir los siempre riesgosos préstamos usurarios a vecinos de la ciudad ${ }^{32}$.

\subsection{Las importaciones}

Desde fines del siglo XVIII, con la apertura del puerto de Arica al comercio libre y el establecimiento de una factoría de los Cinco Gremios en la ciudad, la sociedad arequipeña empezó a revelarse como una gran consumidora de efectos importados, debido no solo al gusto que experimentaban por todo lo foráneo, sino también, a la ausencia de una verdadera industria doméstica y al comportamiento pseudo-aristocrático de buena parte de su población ${ }^{33}$. Posteriormente, durante los primeros años de vida independiente y como consecuencia de la expansión industrial europea, la frecuente necesidad de ingresos en las autoridades locales, los bajos precios alcanzados por tales mercancías y el deseo de incrementar sus ganancias en muchos negociantes, esta situación terminó sobrepasando todos los límites imaginados y los mercados de la región se vieron inundados por una gran cantidad, variedad y calidad de mercancías como, tejidos y prendas de vestir, bisutería en general, licores finos, especias, alimentos en conserva, útiles de escritorio, libros, muebles, vajilla, azogue, varillas de hierro, herramientas de trabajo y hasta, armas, por un valor superior a 500.000 pesos anuales. Claro está, hubo una cierta preponderancia de los tejidos que en promedio representaban más del 90\% de dichas importaciones (Bonilla, 1980). La mayor parte de estos cargamentos provenían de Europa y llegaron consignados directamente desde algunas ciudades del Viejo

32 Aunque algunos comerciantes extranjeros en años posteriores a la Independencia participaron de inciertos proyectos agrícolas o mineros, muy pocos destinaban sus ganancias a los préstamos usurarios. Contrariamente, cada año exportaban a Europa cientos de marcos de plata piña, chafalonía, onzas de oro y miles de pesos fuertes; posiblemente destinados a especulaciones mercantiles o financieras.

33 La composición socioeconómica de la ciudad a fines del siglo XVIII, la obtenemos de numerosos documentos notariales, administrativos y judiciales encontrados en el Archivo Regional de Arequipa (ARAR) y diversos trabajos como:Wibel (1975), Chambers (2003), Brown (2008) y Condori (2017). 
Mundo donde los grandes almaceneros de Arequipa tenían una oficina principal, algún representante comercial o varios proveedores. Ese fue el caso por ejemplo de Gibbs y Compañía (Londres), Jack Hermanos (Liverpool), Le Bris/Viollier (Burdeos) y C. W. Schütte (Hamburgo). Asimismo, otros volúmenes significativos de efectos eran comisionados frecuentemente desde Lima, Valparaíso e incluso Tacna, donde se encontraban asentadas importantes comunidades de comerciantes extranjeros y algunas negociaciones como, Tomás Mac Laughlin, Dickson Price e incluso la propia Casa Gibbs.

Pero, más allá del origen de las mercancías o el punto desde donde las enviaban, lo verdaderamente cierto era que todos los cargamentos al menos oficialmente, debían ingresar por Islay; el principal puerto de Arequipa, inaugurado en agosto de 1827 en reemplazo del incómodo y poco adecuado puerto de Quilca.Aunque el puerto de Arica contaba con mejores condiciones naturales y hasta un muelle de desembarco, los comerciantes arequipeños se inclinaron por Islay, fundamentalmente, por su cercanía a la ciudad $(120 \mathrm{~km})$. Precisamente a partir de 1830 , se estableció en este puerto la Aduana principal y sus almacenes, la fuerza de resguardo y el imponente edificio del cónsul de Gran Bretaña, cargo que recayó desde 1824 en Udny Passmore y a partir de 1837, en el comerciante Tomás Crompton ${ }^{34}$. El incremento de las actividades portuarias de Isla y se reflejó no solo en el número de barcos anclados en su rada sino también en el crecimiento de la población, que para mediados del siglo XIX llegó a tener cerca de 1500 habitantes, entre nacionales y extranjeros. Este último grupo, lo conformaban residentes pobres, empleados ocasionales, pequeños comerciantes y agentes marítimos, vale decir, representantes de las principales casas arequipeñas; quienes se encargaban de pagar impuestos, recibir mercaderías y enviar la carga al extranjero, percibiendo a cambio una pequeña comisión, para lo cual debían de poseer vivienda y almacenes propios. Eran los vecinos más ricos y destacados del pueblo de Santa Rosa de Islay, como los ingleses Diego Bowman, Juan Ward y Patricio Gibson (Condori, 2019).

El comercio de importaciones que alcanzó su momento culmen a mediados de la década de 1840 con la concentración de esta actividad en manos de las grandes casas mayoristas, tuvo un fuerte impacto en los

34 El Republicano, Tomo 5, Número 5, 16 enero 1830. 
ingresos de la Tesorería de Arequipa, en un periodo en que las rentas generales del departamento habían descendido considerablemente (400.000 pesos) en comparación a los últimos años del periodo colonial $(1.000 .000 \text { pesos })^{35}$. Los aportes anuales proporcionados por la aduana principal de Islay por este concepto, en promedio bordeaban los 200.000 pesos anuales, casi el 50\% de las rentas totales. Este impuesto cobrado a las importaciones fue mantenido por las autoridades nacionales entre el 25 y $50 \%$ sobre el valor de las mercancías. Pero, podían crecer aún más, si a este monto le sumábamos las cantidades obtenidas en razón de todas las exportaciones, los préstamos o adelantos que con frecuencia entregaban los extranjeros, a fin de aliviar las urgentes necesidades del gobierno. Entonces, tendríamos una cifra mucho más elevada todavía. Ahora, dependiendo de la coyuntura política, la situación productiva de actividades como la minería o la elaboración de aguardientes e incluso, el estado de las otras rentas departamentales, tales ingresos derivados del comercio podrían transformarse en un verdadero salvavidas para las autoridades políticas y militares locales; como ocurrió en 1847, cuando los aportes de los comerciantes extranjeros, en impuestos y préstamos, representaron nada menos que el $61 \%$ de todo lo recaudado ese año por la hacienda local ${ }^{36}$.

En medio de esta situación de carencias y necesidades permanentes, las autoridades locales y nacionales no parecían tener más opción que dejar de lado, al menos circunstancialmente, sus posiciones políticas, sentimientos nacionalistas o intereses proteccionistas, si verdaderamente existieron, para favorecer la apertura económica, concediendo algunas ventajas comerciales, privilegios fiscales, además de cierta tolerancia religiosa, para aquellos hombres de negocios provenientes de ultramar; porque al final de cuentas, de esta actividad dependían mayormente los ingresos hacendísticos y buena parte de socorros solicitados de manera urgente, para aliviar necesidades tan apremiantes como el pago de salarios desoldados y oficiales, la compra de uniformes y armas, la reconstrucción

\footnotetext{
35 ARAR, Libro Mayor de la Real Caja de Arequipa, 1824.

36 Ese año, los ingresos del tesoro alcanzaron un poco más de 466.000 pesos, los ingresos de aduanas, 190.000 y los empréstitos de los comerciantes, cerca de 77.000 pesos. Ver Meneses (2014).
} 
de infraestructura pública o el traslado perentorio del ejército hacia una nueva zona de conflicto $^{37}$.

\subsection{La comercialización}

La llegada de comerciantes extranjeros acarreando grandes volúmenes de mercancías a la región no significó en teoría la creación de un nuevo espacio económico o la aparición de un gran mercado, sencillamente fue el restablecimiento con modernos integrantes de una parte del viejo circuito comercial que funcionó desde fines del siglo XVI y había logrado integrar una parte del Perú con los mercados mineros de la audiencia de Charcas $^{38}$. Este circuito había quedado desarticulado y fragmentado, a raíz de la crisis política y económica surgida en América del Sur la segunda década del siglo XIX. En consecuencia, pasada la crisis de la independencia, la audiencia de Charcas se convirtió en un estado independiente, Bolivia y la apertura comercial en el sur del Perú, favoreció la creación de nuevas comunidades compuestas por mercaderes europeos, no solo en Arequipa sino también, en Tacna y Arica. Estos últimos, en poco tiempo comenzaron a competir con sus homólogos arequipeños por el control de los mercados bolivianos, aunque de manera más ventajosa, por la menor distancia que los separaba (Rosenblitt, 2011). Todo ello provocó que, frente a la fragmentación del mercado colonial, los comerciantes extranjeros asentados en la Ciudad Blanca buscaran reorganizar y controlar el espacio económico que tenían bajo su influencia y a través de una sólida red de conexiones mercantiles, poder aprovecharlo de manera más eficiente y en su propio beneficio. Precisamente, la apertura del puerto de Quilca y posteriormente de Islay les proporcionó una gran ventaja frente a las comunidades de Tacna o Lima, en relación a la distancia que los separaba de las provincias del interior y los importantes mercados de Puno, Cusco, Apurímac y Ayacucho, que en la práctica equivalía amenores costos por concepto de transporte de mercancías ${ }^{39}$.

37 En 1839, lo comerciantes extranjeros prestaron al gobierno local cerca de 60.000 pesos para atender las urgencias (El Republicano, Tomo 15, Número 71, 23 setiembre 1839).

38 Sobre la conformación del circuito comercial en el siglo XVIII, revisar Galindo (1977).

39 Estos datos han sido tomados de "Razón circunstanciada que Don Matheo Cossío 
Este renovado circuito comercial que partía del puerto de Islay, tenía su epicentro en la ciudad de Arequipa, donde se hallaban instalados los grandes almacenes extranjeros y se extendía de manera concéntrica, hacia las regiones aledañas, comprometiendo a su pasono solo a los ya citados mayoristas, sino también a medianos comerciantes, tendederos, comerciantes itinerantes, representantes provincianos, arrieros y hasta comerciantes al menudeo o mercachifles. Debido a un decreto gubernamental, los extranjeros estuvieron imposibilitados, bajo pena de multa, expender sus productos al menudeo dentro de la ciudad y en las provincias del interior; con ello, las autoridades nacionales buscaron proteger las actividades de los "naturales y ciudadanos del Perú" no tan competitivos; sin embargo, muchos extranjeros recurrieron a distintas estrategias para incumplirlo, por ejemplo, a través de la contratación de dependientes nacionales ${ }^{40}$.

En general, las ventas en los almacenes y tiendas mayoristas se realizaban al crédito, cobrando un interés de $1 / 2 \%$ al mes y por plazos comprendidos entre dos y cuatro meses en promedio, previa garantía de un aval, una propiedad o las correspondientes mercancías adquiridas. Con respecto a las cantidades entregadas- ya habían quedado atrás los alocados años en que se entregaban mercancías bajo la única condición de "ser originario del país"-estas dependían dela categoría del vendedor, la capacidad de pago del comprador, las condiciones del mercado e incluso del lugar de residencia de los solicitantes; vale decir, los comerciantes de la ciudad recibían casi siempre mayores montos que aquellos avecindados fuera de ella. Una de las razones pudo haber estado relacionada con la facilidad y cercanía para realizar los cobros o la rapidez a la hora de solicitar la intervención de las autoridades judiciales y de comercio, en caso de presentarse moras, quiebra o iliquidez de los antes mencionados $^{41}$.

diputado del comercio de Arequipa produce al Real Tribunal del Consulado de Lima con relación a los ramos de Industria de aquella provincia" (Cossío, [1804] 1964).

40 En 1829 el diputado de Arequipa Pedro José Gamio, un ex comerciante, solicitó al Ministro de Hacienda "que los almacenes de los extranjeros se situasen en los puertos y no en el interior, y que las consignaciones se dirijan a los comerciantes del país" (Meneses, 2014, p. 89-90).

41 ARAR, Protocolos Notariales. Juan José Salazar 846, 14 de enero de 1853, fol. 185. 
Al interior de la ciudad de Arequipa, progresivamente se fue advirtiendo durante estos años una serie de cambios de carácter económico y social generados por el aumento de las importaciones, el abaratamiento de productos textiles y la expansión del consumo en los grupos menos favorecidos. Entre los más importantes, tenemos la formación de numerosas compañías o sociedades mercantiles, la multiplicación de pequeñas tiendas y de comerciantes al menudeo ${ }^{42}$ y lo más deplorable, el incremento de la criminalidad relacionada con robos a establecimientos de comercio, ya no solo a pequeños negocios como era común en el periodo colonial (Condori, 2017), sino también a almacenes de grandes mayoristas, como Le Bris, Schütte y Samuel Went, y lo que resulta más sorprendente, en los propios almacenes de la aduana de Arequipa ${ }^{43}$. Como corolario de todo ello, se desencadenó una feroz competencia entre comerciantes menores con el objetivo de alcanzar una mayor participación en el mercado local, empujándolos a endeudamientos excesivos, que terminaron en muchas ocasiones con la suspensión de los pagos a sus proveedores o incluso en algo peor, la quiebra de los respectivos negocios. Este fenómeno crítico lamentablemente se incrementó a fines de la década de 1840, provocando grandes inconvenientes para los comerciantes mayoristas, sobre todo al intentar cobrarlas enormes deudas contraídas ${ }^{44}$.

El hacer efectivas las deudas, impagas o retrasadas, durante estos años, fue siempre una tarea complicada para los acreedores, debido a factores como la inestabilidad política, los cambios permanentes de autoridades, la fuga o muerte de los deudores y hasta la poco desarrollada cultura de pago de ciertos individuos. Si a todo ello le sumamos, los estrechos márgenes de ventas, ganancias e inversiones de algunos acreedores, el resultado será indefectiblemente la multiplicación de demandas ante las autoridades judiciales, en una época donde aún estaba pendiente la redacción de una legislación actualizada que normara sobre estos casos y en su ausencia, permanentemente se apelaba a los reglamentos colo-

42 En los años posteriores a la promulgación del reglamento de Comercio Libre, el número de tiendas y comerciantes minoristas experimentó un notable crecimiento, pasando de 112 locales en 1785 a cerca de 400 a fines de ese mismo siglo.VerWibel (1975) y Condori (2014).

43 ARAR, Prefectura 1,11 de julio de 1825.

44 ARAR, Corte Superior, Causas Civiles 179, 4 de marzo de 1845, folios 24, 27 y 57. 
niales, como la Novísima Recopilación de Leyes (1805) o las Ordenanzas de Bilbao (1737). Las cosas se complicaban aún más si el deudor residía en una provincia alejada, donde era muy difícil solicitar la intervención de las autoridades políticas o militares. Frente a esta realidad poco esperanzadora, algunos comerciantes extranjeros con mayores volúmenes de mercancías y créditos buscaron solucionar el problema directamente mediante diversos procedimientos. En primer término, se buscó permanentemente la conciliación o arreglo amistoso con los deudores, refinanciando la deuda, condonando los intereses, otorgando nuevos plazos de pago e, incluso, proporcionando pequeñas cantidades de mercancías a crédito a fin de que no se paralicen sus actividades y continúen con los pagos. El objetivo de todo ello buscaba evitar los procesos judiciales, que no solo eran largos y costosos, sino que, algunas veces terminaban beneficiando al deudor (Haigh, 1967; Bonilla, 1975). Otra práctica recurrente de cobro buscó la cancelación de los créditos atrasados a través de la entrega de pequeñas cantidades en dinero de forma semanal o mensual hasta su extinción definitiva, lo cual permitía asegurar la devolución por lo menos de una parte del monto principal. Ahora, cuando el insolvente o moroso residía en una provincia alejada, se otorgaban poderes a conocidos viajeros o comerciantes instalados en aquella región. En ciertas ocasiones, cuando algún comerciante tenía deudas no con uno sino con varios proveedores o almaceneros de la ciudad, los acreedores unían sus esfuerzos con el único objetivo de lograr la recuperación de sus préstamos, entregando poderes generales a un representante en común ${ }^{45}$.

El uso de la justicia, encabezada por el juez de comercio, casi siempre se realizaba en última instancia y por lo general, terminaba con el embargo de alguna propiedad, sea esta un cuarto, una casa, chacra, hacienda o las mismas mercancías entregadas; en caso de tratarse de una propiedad inmueble, esta se tasaba y luego vendía al mejor postor (casi siempre otro comerciante) y el monto de lo obtenido, se repartía equitativamente, en base a los créditos proporcionados. A lo largo de este periodo, no se encontraron muchos casos de venta o compra de deudas

45 ARAR, Protocolos Notariales, Mariano Prieto 800, 5 de marzo, fol. 31; Juan José Salazar 846, 14 de enero de 1853, fol. 185 y Mariano Prieto 800, 11 de setiembre de1846, fol. 15. 
impagas, de parte de un comerciante o casa comercial, a diferencia de otras regiones, como por ejemplo Tacna, donde destacó la casa inglesa Hainsworth (Rosenblitt, 2017).

\subsection{Las exportaciones}

A diferencia de las importaciones, abundantes y variadas, los productos extraídos desde el Perú por los comerciantes extranjeros en la primera mitad del siglo XIX fueron bastante limitados, generando un problema de costos y retornos para los armadores extranjeros y de desabastecimiento de metálico para la economía regional. Según su naturaleza, tales productos pueden ser divididos en dos rubros: metales preciosos y materias primas. El primero de ellos, vale decir la extracción de metales preciosos, en forma de plata piña y chafalonía, oro en polvo, pasta y en moneda corriente, representó para muchos comerciantes un complemento a sus actividades de importación y comercialización de efectos y por el volumen que estas exportaciones alcanzaron en algún momento, se puede entender que las actividades de muchos de ellos fueron altamente lucrativas, como no se tiene conocimiento en épocas anteriores ${ }^{46}$.Valdría la pena contextualizar ese éxito, para tener una idea cabal de la dimensión de sus negocios.

Desde el siglo XVI, las principales fuentes de metales preciosos y por tanto de capital circulante, habían sido las minas del Perú y de la audiencia de Charcas, la actual república de Bolivia. Con la Independencia, muchas de estas minas arruinadas por el conflicto fueron abandonadas y otras, debido a diversos factores redujeron enormemente su ya exigua producción. Aunque, a inicios de la república se conformaron numerosas compañías mineras con capitales extranjeros a fin de reactivarlas, la mayor parte de estos proyectos terminaron en rotundos fracasos (Condori, 2014). En relación al departamento de Arequipa, la producción de

\footnotetext{
46 A principios de 1825el H.B.M. Mersey trasladó cerca de 331.000 pesos de plata acuñada, pertenecientes a las principales casas y comerciantes extranjeros avecindados en la ciudad de Arequipa como Dickson Price (108.000 pesos), Wyllie Miller (50.000 pesos), Gibbs Crawley (60.000 pesos), Guillermo Hodgson (40.000 pesos), Ibáñez y Marcó del Pont (20.000 pesos), entre otros; pagando 1 1 $1 / 2$ peso por cada mil, por llevar el dinero, contarlo y guardarlo "además de 2 pesos por cada juego de conocimientos de embarque". (Witt, 1992, p. 84)
} 
plata entró en una escala depresiva a partir de 1820 y de ella solo escaparía a fines del siglo XIX (Condori, 2016b); en ese sentido, el aporte de la minería argentífera a la economía regional no fue capaz de satisfacer las necesidades del mercado local y menos aún, las demandas del comercio de importaciones, obligando a negociantes nacionales y extranjeros a la permanente búsqueda de nuevas fuentes de aprovisionamiento de metales preciosos en las ciudades, pueblos y centros mineros de provincias y fuera del departamento.

Un ejemplo del éxito podemos observarlo en aquella firma comercial propiedad de los hermanos Juan, Santiago y Carlos Jack, naturales de la ciudad de Elgin en Escocia, quienes en 1824 abrieron su primera dependencia en Arequipa. Esta firma, conocida como Jack Hermanos y Compañía (Jack Brothers \& Co.), logró consolidarse como una de las grandes empresas extranjeras durante la primera mitad del siglo XIX, incluso por encima de negociaciones como la casa Gibbs, Mac Laughlin, Viollier y Schütte. No era para menos, entre 1846 y 1851, extrajeron por el puerto de Islay con destino a Liverpool, donde tenían una oficina principal, 11.198 onzas de oro y 44.545 marcos de plata piña, por un valor superior a 500.000 pesos. Esta cifra resulta bastante considerable, si la comparamos con la producción total de plata del departamento entre 1830 y 1835 que fue 58.680 marcos y sorprende aún más, tratándose de una sola casa comercial (Condori, 2018). De otro lado, si observamos las cifras de extracción de metales preciosos en forma conjunta, es decir, incluyendo a los principales comerciantes de la ciudad y tomando como base un solo año, estas parecen incluso más impresionantes. Por ejemplo, el año 1846 cuando se extrajeron por el puerto de Islay 22.079 marcos de plata piña, 3.301 marcos de plata chafalonía, 7.473 onzas de oro en pasta y polvo, 1.530 onzas de oro selladas y 133.446 pesos en plata amonedada ${ }^{47}$.

Precisamente, aquí tenemos la cara menos agraciada del comercio extranjero y no solo en Arequipa: la fuga de capitales y las pocas inversiones directas en la economía regional durante estos críticos años. A la larga, tal situación se convirtió, en un motivo de queja permanente para los comerciantes y hacendados locales ante las autoridades regionales y nacionales; además de ser, una de las causas de la animosidad existente

47 El Republicano, Tomo 20, enero-diciembre de 1846. 
contra los extranjeros y el origen de continuos pedidos para su expulsión definitiva del país. No era para menos, en 1841 Santiago Jack, en sociedad con el comerciante inglés Samuel Went, solicitó una licencia al prefecto del departamento para extraer nada menos que 40.000 marcos de plata piña por el puerto de Islay, mediante la entrega de 10.000 pesos como adelanto por los derechos de exportación, licencia que fue aprobada poco después por el mismísimo presidente Agustín Gamarra ${ }^{48}$. Al respecto, el viajero francés Eugenio de Sartiges, no obstante, haber permanecido poco tiempo en el Perú, pudo advertir muy bien la naturaleza de este problema:

Los americanos españoles tienen pocos productos indígenas que dar a cambio de las mercaderías de Europa y se ven forzados a pagarlas en dinero. Ese dinero una vez que está en la caja del negociante extranjero, infaliblemente se traslada a Europa. Por eso muchas veces se han presentado peticiones a las cámaras peruanas, tendientes a expulsar del país a los comerciantes extranjeros a fin de impedir esa exportación de divisas monetarias y el mismo pedido se renueva en cada conmoción política. (Sartiges, 1973, p. 156)

Afortunadamente, dicha situación habría de cambiar algunas décadas después de la visita de Sartiges, por iniciativa de los propios comerciantes extranjeros, quienes comenzaron a inclinarse en torno a algunos productos nativos de alta demanda en el mercado europeo, como cascarilla, lana de ovejas y fibra de camélidos. Aunque tales mercancías ya eran exportadas a Europa desde fines del siglo XVIII, su crecimiento y expansión se produjo recién en el siglo XIX, aunque no de manera simultánea. El primer turno le correspondió a la cascarilla o corteza de la quina, posteriormente, a la lana de ovejas y a partir de 1840, se inició el boom de la fibra de camélidos, especialmente de alpaca, caracterizada por su gran fineza y resistencia. Ese año, las exportaciones de fibra de alpaca hacia el mercado industrial inglés fueron de 7940 libras y diez años después, alcanzaron la astronómica cifra de 1.638.140 libras (Bonilla, 1977). En este nuevo negocio participaron activamente las grandes casas mayoristas, sus dependientes y representantes en los pueblos del interior. Su consolidación se logró definitivamente en la segunda mitad

48 ARAR, Protocolos Notariales, José María Pastor 763, 4 de agosto de 1841, fol. 240. 
del siglo, con el surgimiento de nuevas casas comerciales como Forga, Stafford, Braillard y Ricketts.

En definitiva, la crisis económica de la post independencia llegó a su fin a mediados del siglo XIX, gracias a la fibra de camélidos, convertida en el principal producto de exportación y riqueza de la región, por lo menos hasta las primeras décadas del siglo siguiente. Durante esos postreros años, Arequipa vivió una etapa de prosperidad y bienestar que no se observaba desde fines del periodo colonial y consolidó a la ciudad del Misti, como el mayor centro político, comercial y financiero del sur del Perú, sobre todo a partir de la década de 1870, gracias a la construcción del Ferrocarril de Arequipa, que vinculó la capital del departamento con los prósperos centros de producción lanera y minera localizados en las zonas altas de Arequipa, Puno y Cusco.

\section{Consideraciones finales}

Finalmente, en esta última parte reflexionaremos acerca de las relaciones entre los comerciantes extranjeros y la sociedad local, así como sus aportes a la vida política, social y cultural de la ciudad. Acerca del primer tema, el profesor D. C. M. Platt (1973, p. 40) afirmaba en su reconocido estudio que, "los hombres de negocios británicos rara vez echaron raíces en las repúblicas". Frente a ello, nosotros debemos decir que no siempre ocurrió de ese modo. Muchos comerciantes británicos no solo se casaron con mujeres de la localidad, sino que echaron raíces tan profundas que perduran hasta nuestros días y ese fue el caso de familias como Ricketts, Roberts, Gibson y Mitchell. La afirmación del profesor Platt, podría ser válida sólo para algunos de los grandes almaceneros de la ciudad y no solo británicos, como los hermanos Juan y Santiago Jack, Daniel Schütte, Santiago Le Bris y Andrés Viollier, quienes luego de alcanzar el éxito en los negocios, se retiraron a sus países o ciudades de origen y una vez allí, contrajeron matrimonio.

Un caso intermedio entre ellos, sería el de Cristóbal Guillermo Schütte, natural de Bremen, quien se casó en Arequipa en 1835 con Rosa Diez de la Torre, pero terminó residiendo en Paris a fines del siglo XIX, luego de haber acumulado una fortuna en el negocio del guano y después de casi medio siglo de residencia en el Perú. Todo ello, nos 
lleva a pensar que, la elección de la residencia estuvo determinada entre otras razones por las posibilidades de enriquecimiento, en la medida que la mayoría de los que lo consiguieron terminaron sus días en el extranjero, en comparación a los medianos y pequeños comerciantes. En ese sentido, el aporte de estos grandes empresarios de la primera mitad del siglo XIX, a la cultura, la educación y la vida urbana de la ciudad fue insignificante, debido precisamente a los objetivos que perseguían.

Contrariamente, fueron los descendientes de los medianos comerciantes arraigados en suelo arequipeño, como Enrique W. Gibson, Federico Marriot Rivero, Eduardo de Poncignon y otros más, quienes terminaron integrándose dentro de la sociedad local, participando de forma comprometida en actividades políticas, culturales, institucionales y de fomento. No solo a través de su labor de comerciantes o autoridades municipales, sino particularmente, como promotores y protagonistas activos en la fundación de las primeras instituciones de carácter socio-cultural, financiera y empresarial de la región, como el Club Arequipa (1871), el Banco de Arequipa (1871-1882) y la Cámara de Comercio e Industria de Arequipa (1887).

\section{Referencias}

ANNA, Timothy. La caída del gobierno virreinal en el Perú. Lima: Instituto de Estudios Peruanos, 2003.

BONFIGLIO, Giovanni (Org.). La presencia europea en el Perú. Lima: Fondo Editorial del Congreso del Perú, 2001.

BONILLA, Heraclio (Org.). Gran Bretaña y el Perú 1826-1919: informes de los cónsules británicos, v. 1. Lima: Instituto de Estudios Peruanos - Fondo del Libro del Banco Industrial del Perú, 1975.

BONILLA, Heraclio. Gran Bretaña y el Perú: los mecanismos de un control económico, v. 5. Lima: Instituto de Estudios Peruanos - Fondo del Libro del Banco Industrial del Perú, 1977.

BONILLA, Heraclio. Un siglo a la deriva. Ensayos sobre el Perú, Bolivia y la Guerra. Lima: Instituto de Estudios Peruanos, 1980.

BOYD-BOWMAN, Peter. Patterns of Spanish emigration to the New World (14931580). Special Studies, Nueva York, n. 34, p. 1-101, 1973.

BROWN, Kendall. Borbones y aguardiente: la reforma imperial en el sur andino. Arequipa en vísperas de la Independencia. Lima: Instituto de Estudios Peruanos- Banco Central de Reserva del Perú, 2008. 
BULLER, Carlos. Vinos, aguardiente y mercado: auge y declive de la economía del vino en los valles de Arequipa (1770-1853). Lima: Quellca, 2011.

CHAMBERS, Sarah C. De súbditos a ciudadanos: honor, género y política en Arequipa 1780-1854. Lima: Red para el Desarrollo de la Ciencias Sociales en el Perú, 2003.

CONDORI, Víctor. Arequipa y la Independencia, 1821-1824. Revista Illapa, n. 4. p. 57-74, Lima, 2009.

CONDORI,Víctor. Los efectos económicos de la Independencia en Arequipa: 18201824. In: CONTRERAS, Carlos; MAZZEO, Cristina; QUIROZ, Francisco (Org.). Guerra, finanzas y regiones en la historia económica del Perú. Lima: Instituto de Estudios Peruanos-Banco Central de Reserva del Perú, p. 173-218, 2010.

CONDORI,Víctor. Guerra y economía en Arequipa: las actividades del español Lucas de la Cotera en una coyuntura de crisis, 1821-1824. Revista de Indias, Madrid, v. 71, n. 253, p. 827-858, 2011.

CONDORI,Víctor. El francés Santiago Le Bris y la primera casa comercial extranjera en Arequipa, 1821-1850. Bulletin de l'Institut Français d'Études Andines, v. 42, n. 2, p. 261-283, Lima, 2013.

CONDORI,Víctor. Economía y empresa en Arequipa a inicios de la República, 18251850. Economía, v. 37, n. 74, p. 163-212, Lima, 2014.

CONDORI,Víctor. Entre la crisis económica y la migración alemana. Las actividades del comerciante Cristóbal Guillermo Schutte en Arequipa, 1827-1850. Jahrbuchfür Geschichte Lateinamerikas, Colonia, n. 53, p. 143-184, 2016 a.

CONDORI,Víctor. Minería y empresa en Arequipa: las minas de Caylloma durante el siglo XIX. Revista de Investigación, Arequipa, v. 7, p. 31-50, $2016 \mathrm{~b}$.

CONDORI,Víctor. Robos, hurtos y asesinatos en Arequipa a fines de la Colonia, 1780-1824. Arequipa: Universidad Católica San Pablo, 2017 (Tesis de Maestría en Historia).

CONDORI,Víctor. Poder británico y mercado en Arequipa. La casa Jack Hermanos y Compañía, 1824-1853. Historia, Santiago de Chile, v. 51, n. 2, p. 87-116, 2018.

CONDORI,Víctor. Entre el comercio internacional y la economía local: el puerto mayor de Islay, 1827-1876. 2019. Inédito.

COSSÍO, Matheo. Razón circunstanciada que Don Matheo Cossío diputado del comercio de Arequipa produce al Real Tribunal del Consulado de Lima con relación a los ramos de Industria de aquella provincia. Revista del Archivo Nacional, Lima, n. 28, p. 219-233, 1964.

DONGHI, Tulio Halperín. Hispanoamérica después de la independencia: consecuencias sociales y económicas de la emancipación. Buenos Aires: Paidós, 1972.

FISHER, John. Minas y mineros del Perú colonial 1776-1824. Lima: Instituto de Estudios Peruanos, 1977.

GALINDO, Alberto Flores. Arequipa y el sur Andino: siglos XVIII-XX. Lima: Editorial Horizonte, 1977.

HAIGH, Samuel. Bosquejos del Perú (1825-1827). In:TAURO,Alberto (Org.). Viajeros en el Perú republicano. Lima: Universidad Nacional Mayor de San Marcos, p. 13-43, 1967. 
HUMPHREYS, Robert (Org.). British Consular Reports on the trade and politics of Latin America, 1824-1826.London: Offices of the Royal Historical Society, 1940.

HUMPHREYS, Robert. British merchants and south American independence. Proceedings of the British Academy, Oxford, n. 51, p. 151-174, 1965.

MARICHAL, Carlos. Historia de la deuda externa en América Latina. Madrid: Alianza Editorial, 1992.

MAZZEO, Cristina (Org.). Los comerciantes limeños a fines del siglo XVIII: capacidad y cohesión de una elite 1750-1825. Lima: Pontificia Universidad Católica del Perú, 2000.

MENESES, Betford Betalleluz. Población y fiscalidad en Arequipa a inicios de la República. Lima: Pontificia Universidad Católica del Perú, 2014 (Tesis de Maestría en Historia).

MILLER, John. Memorias del General Guillermo Miller, tomos I-II. Lima: Editorial Arica, 1975.

MILLS, John. Rosehaugh: a house of its time. Inverness-Scotland: Avoch Heritage Association Rosehaugh, 1997.

PAZ-SOLDÁN, Eusebio Quiroz. Aspectos económicos de la independencia de Arequipa 1790-1830. 1976. Arequipa: Universidad Nacional de San Agustín, Arequipa, 1976 (Tesis de Doctorado en Historia).

PLATT, D. C. M. Latin America and British Trade, 1806-1914. The Merchant Adventurers. Nueva York: Barnes \& Noble, 1973.

ROSENBLITT, Jaime. Centralidad geográfica, marginalidad política: la región Tacna-Arica y su comercio, 1778-1841. Santiago: Pontificia Universidad Católica de Chile, 2011 (Tesis de Doctorado en Historia).

ROSENBLITT, Jaime. Los negocios de la casa Hainsworth y Compañía en Tacna y Arica, 1841-1868. Una mirada al comercio regional. América Latina en la Historia Económica, México, v. 24, n. 3, p. 41-70, 2017.

SARTIGES, Eugenio de.Visita de Arequipa, 1834. In: NUÑEZ, Estuardo (Org.). El Perú visto por viajeros, tomo 1. Lima: Ediciones PEISA, p.155-172, 1973.

TRISTÁN, Flora. Peregrinaciones de una Paria, v. 1. Arequipa: Editorial UNSA, 1997.

VILLA ESTEVES, Deolinda. La elite comercial limeña entre el comercio libre y la Guerra de la Independencia: el caso de Antonio de Elizalde. In: MAZZEO, Cristina (Org.) Los comerciantes limeños a fines del siglo XVIII: capacidad y cohesión de una elite, 1750-1825. Lima: Pontificia Universidad Católica del Perú, p. 133-173, 2000.

WIBEL, John. The evolution of a regional community within empire Spanish and Peruvian nation: Arequipa 1780-1845. Palo Alto: Stanford University, 1975 (Tesis de Doctorado en Historia).

WITT, Heinrich. Diario 1824-1890. Un testimonio personal sobre el Perú del siglo XIX. Tomos 1-2. Lima: Banco Mercantil, 1992. 